\title{
Study of gastric acid secretion in hookworm duodenitis
}

\author{
S. RAJU AND F. M. NARIELVALA \\ From the Peptic Ulcer Research Unit and the Department of Medicine \\ (Gastroenterology), Christian Medical College, Vellore, South India
}

EDITORIAL SYNOPSIS An increased basal secretion has been demonstrated in hookworm duodenitis and its significance is discussed in relation to duodenal mucosal damage with consequent release of gastrin.

The importance of the participation of the duodenum in the 'gastrin phase' of gastric acid secretion has been brought to light only recently (Lai Kai Sum, 1963). With the duodenal mucosa elaborating large quantities of gastrin, it is a logical progression of inquiry to determine the scope and role of duodenal mucosal changes, such as inflammation, in evoking significant variations in acid secretion. The occurrence of duodenitis in ancylostomal infestation is well documented (Bonne, 1942; Hodes and Keefer, 1945).

The results of acid secretion studies undertaken on carefully selected subjects with ancylostomiasis balanced with appropriate controls or normals are presented in this paper. The pattern of acid secretion in subjects with chronic duodenal ulcer without commensal hookworm infestation has also been collated.

\section{SELECTION OF MATERIAL}

A substantial proportion of the village population for this study has been drawn from an area (Table I) where hookworm infestation is deeply endemic (Rao, Klontz, Benjamin, Rao, Almas Begum, and Dumm, 1960; Centerwall and Narielvala, 1964). Consequently hookworm infestation is often an incidental finding in several disease states, which may modify

TABLE I

PREVALENCE OF HOOKWORM INFECTION IN A RURAL POPULATION

\begin{tabular}{ccc} 
Village & $\begin{array}{c}\text { Number } \\
\text { Studied }\end{array}$ & $\begin{array}{l}\text { Prevalence } \\
\text { of Hookworm } \\
(\%)\end{array}$ \\
\hline Pannathur & 448 & 44.6 \\
Sholavaram & 342 & 38.0 \\
Crown & 110 & 33.5 \\
Total no. studied 900; average prevalence of hookworm $40.7 \%$. \\
'Villages close to Vellore.
\end{tabular}

or affect acid secretion, e.g., anaemias, tropical sprue, chronic peptic ulcer, malnutrition, but it was possible to obtain a homogeneous material for study with 'pure' ancylostomal duodenitis unassociated with the diseases mentioned above. The following three chief and more common conditions that demanded special attention were investigated further.

ANAEMIA A routine haemoglobin determination was carried out in each subject. On the basis of normal haemoglobin values as determined in 2,242 blood donors attending this hospital, those subjects with haemoglobin levels of $12 \mathrm{~g} . \%$ or below were excluded as potentially unsuitable for the investigation.

DUODENAL ULCER Although the clinical picture of ancylostomal duodenitis does not usually present any kinship with the clinical picture of chronic duodenal ulcer, it has not infrequently been observed to mimic it closely. Furthermore, an association of silent duodenal ulcer cannot be ruled out without radiological scrutiny. The radiological appearances of helminthic (ancylostomiasis in particular) duodenitis have been studied by Hodes and Keefer (1945). The evidence of chronic duodenal ulcer, viz., crater or niche, and/or scarred duodenal bulb with constant deformity, were looked for in each of the subjects, and any suspicion of such evidence led to rejection of the case.

MALABSORPTION SYNDROME Vellore and its rural environs has a high incidence of sprue or tropical malabsorption syndrome with nutritional sequelae (Baker, Mathan, and Joseph, 1936), so in addition to clinical scrutiny a full barium meal and faecal fat estimations for steatorrhoea were of help in detecting and eliminating such cases from the material studied. 
MATERIAL

GROUP I Fifty-nine subjects (43 males and 16 females) with proven hookworm infestation were chosen, according to our criteria (Table II).

\section{TABLE II}

NUMBERS STUDIED

Hookworm 'Control' $\begin{aligned} & \text { Duodenal } \\ & \text { Ulcer }\end{aligned}$

\begin{tabular}{llcc} 
& & Ulcer \\
\hline Males & 43 & 19 & 102 \\
Females & 16 & $\overline{19}$ & $\overline{102}$
\end{tabular}

GROUP II On the basis of three consecutive stool examinations by the flotation method, 19 'normal' or control subjects were included. These were apparently healthy volunteers with a satisfactory nutritional state, residing in the same area as the subjects of group I and belonging to the same socio-economic strata. Any history suggestive of gastrointestinal disorder past or present was carefully enquired into, and those with a positive history were eliminated from this group. A haemoglobin estimation was carried out in all to confirm levels not below $12 \mathrm{~g} . \%$.

GROUP III One hundred and two cases of uncomplicated duodenal ulcer, proven by barium meal $x$-ray examination or by subsequent surgery, were also incorporated for comparison. These were free from any overlay of hookworm infestation.

Groups I and II were comparable with regard to age and weight distribution (Table III).

\section{TABLE III}

AGE AND WEIGHT DISTRIBUTION OF SUBJECTS STUDIED

43 Cases of 19 Normal 102 Cases of Hookworm 'Controls' Duodenal Ulcer

Males

Mean age $^{1} \pm$ S.D. $\quad 31 \cdot 3 \pm 11 \cdot 0 \quad 27 \cdot 6 \pm 5 \cdot 9 \quad 36 \cdot 1 \pm 9 \cdot 7$

Mean weight ${ }^{2}(\mathrm{~kg}$.) \pm S.D. $50.8 \pm 8 \cdot 5 \quad 52 \cdot 6 \pm 9 \cdot 0 \quad 51 \cdot 7 \pm 6.3$

Females (16)

Mean age $34 \cdot 2 \pm 10 \cdot 9$

Mean weight (kg.) $42 \cdot 0 \pm 8 \cdot 5$

${ }^{1}$ No significant difference between hookworm and control groups. Duodenal ulcer group significantly different from control group $(P<0.01)$ and hookworm group $(P<0.05)$.

${ }^{2}$ No significant difference between the three groups.

\section{METHODS}

An obligatory preliminary screening study, including haemoglobin estimation, barium meal series, and stool examination for faecal fat output, was undertaken. In 20 of the 59 subjects with ancylostomiasis an ova count was done on a 24-hour faecal collection using Stoll's method
(Stoll, 1923). The method of collection and estimation of gastric acid secretion was the augmented histamine test of Kay (1953), as modified by Card and Marks (1960).

The control group of subjects and those with ancylostomiasis were investigated as out-patients under similar conditions. All the subjects belonging to these two groups were undergoing acid secretion studies for the first time and none had been previously subjected to similar investigations.

In 12 subjects of the ancylostomiasis group the augmented histamine test was repeated after the conventional antihelmintic treatment with tetrachlorethylene (4 ml. at a time). In most a second dose, and, in a few even a third dose, was found necessary to eliminate the infestation, which was established after no fewer than three separate stool examinations employing the flotation method. After a radical antihelmintic response was obtained the augmented histamine test was repeated after a period of four to 11 weeks. It was assumed that during such a period the duodenitis might resolve, and might be reflected in a change of gastric acid secretion.

\section{RESULTS}

A significant difference $(P<0.01)$ was obtained in the values for the basal acid output (B.A.O.) with higher values in the ancylostomiasis group than in the control group of normals (Table IV). The posthistamine response, or, the maximal acid output (M.A.O.) was found to remain at normal levels with no appreciable difference between these two groups (Table V). The B.A.O./M.A.O. ratio was also significantly different $(P<0.05)$ between the two groups (Table VI).

The results allow an interesting comparison with the mean acid secretion values obtained in 102 duodenal ulcer cases. Whereas the B.A.O. value is high in the ancylostomiasis group, it is less than in the duodenal ulcer subjects. The difference is significant $(P<0.01)$. The maximum acid output revealed a similar and significant difference with a considerably higher mean value for the duodenal

\section{TABLE IV}

BASAL ACID OUTPUT IN HOOKWORM AND CONTROL GROUPS

\begin{tabular}{lccl} 
Mean & $\begin{array}{l}\text { Hookworm } \\
(59)\end{array}$ & $\begin{array}{l}\text { Control } \\
(19)\end{array}$ & Significance \\
\hline Males (43) mEq./hr. & 4.6 & 2.7 & $\mathbf{P}<0.01$ \\
Females (16) mEq./hr. & 4.3 & - & -
\end{tabular}

TABLE V

MAXIMAL ACID OUTPUT IN HOOKWORM AND 'CONTROL' GROUPS

Hookworm Control Significance (59)

Males (mEq./hr.)

Females (mEq./hr.)

$\begin{array}{lll}20 \cdot 8 & 17 \cdot 9 & \begin{array}{l}\text { Not } \\ \text { significant }\end{array} \\ 17 \cdot 6 & - & -\end{array}$


TABLE VI

B.A.O./M.A.O. RATIO IN NORMAL, HOOKWORM, AND DUODENAL ULCER SUBJECTS

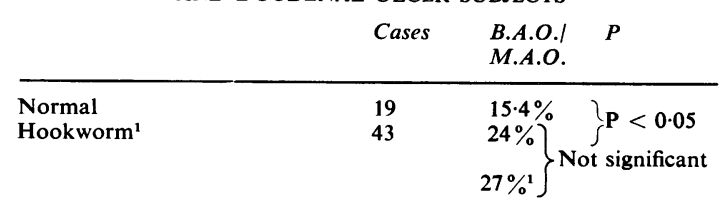

Duodenal ulcer

M.A.O.

10-20 mEq.

21-30 mEq.

$31-40 \mathrm{mEq}$.

$41 \mathrm{mEq}$. and over

$\begin{array}{ll}25 & 27 \cdot 1 \% \\ 37 & 26 \cdot 3 \% \\ 19 & 25 \cdot 9 \% \\ 21 & 33 \cdot 3 \%\end{array}$

${ }^{1}$ B.A.O./M.A.O. ratio in 16 hookworm subjects (females) $27 \%$. ${ }^{2}$ For M.A.O. range $10-40 \mathrm{mEq}$.

ulcer group (Table VII). The B.A.O./M.A.O. ratio, however, does not record a significant difference between the hookworm and ulcer groups, thereby showing a proportionate increment in both B.A.O. and M.A.O. values in the duodenal ulcer patients over those in the hookworm group.

\section{TABLE VII}

ACID SECRETION IN HOOKWORM AND DUODENAL ULCER GROUPS

$\left.\begin{array}{lll}\text { Hookworm } & \begin{array}{l}\text { B.A.O. } \\ (m E q . / h r .)\end{array} & \begin{array}{l}\text { M.A.O. } \\ (m E q . / h r .)\end{array} \\ \hline 43 \text { cases (males) } & 4 \cdot 6 \\ 102 \text { cases (males) } & 6.6\end{array}\right\} \begin{aligned} & \begin{array}{l}\text { S }<0.01 \\ \text { Significant }\end{array} \\ & \begin{array}{l}\mathrm{P}<0.01 \\ \text { Significant }\end{array}\end{aligned}$

On the basis of Stoll's method the 'worm load', obtained from the ova count of an aliquot of a 24-hour faecal collection, was estimated in 20 subjects. Three of these had an ova count over 1,000 per gram of faeces (Fig. 1). The majority in this sampled study, however, seemed to harbour only a mild infestation. This observation may have suffered from the strict selection of cases, particularly from the exclusion of those of hookworm anaemia.

Radiological evidence of 'duodenitis' was discernible in all the 59 subjects with ancylostomiasis. The intensity of the changes varied from mild to severe, but did not yield any relationship to the calculated 'worm load' in the 20 subjects studied. In

TABLE VIII

ACID SECRETION IN HOOKWORM SUBJECTS BEFORE AND AFTER VERMIFUGE

$\begin{array}{lll}\text { No. of Cases } & \text { B.A.O. } & \text { B.A.O. } \\ & \text { Before } & \text { After } \\ & \text { Treatment } & \text { Treatment } \\ & \text { (mEq./hr.) } & \text { (mEq./hr.) }\end{array}$

12

$5 \cdot 5 \quad 4 \cdot 1$

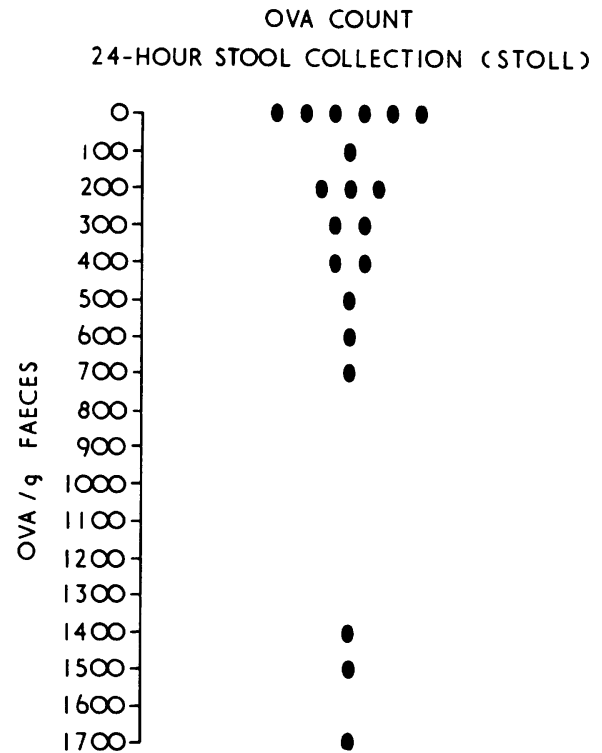

FIG. 1. Ova count on a 24-hour collection of stools in 20 cases.

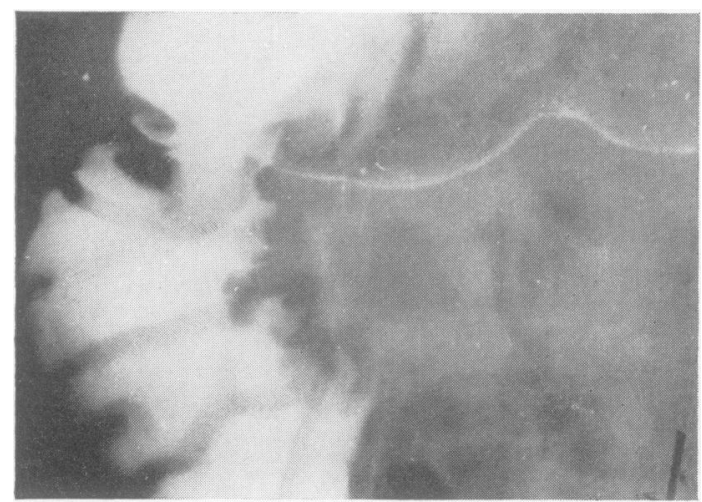

FIG. 2. Ancylostomal duodenitis.

12 it was possible to repeat the augmented histamine test after a period of over four weeks following a satisfactory antihelmintic course of treatment (Table VIII). The basal acid output seemed to drop, but this was not proved statistically significant. The study, however, has to be extended to a larger number and the acid secretion study repeated after a longer period subsequent to de-infestation, taking due care to eliminate the possibility of re-infestation.

\section{DISCUSSION}

The accuracy of the augmented histamine test as an investigatory procedure has been well established, yielding a satisfactorily low coefficient of variation (Card and Marks, 1960; Marks, 1961). Table IX 
shows the results in 38 tests carried out on 17 duodenal ulcer and normal subjects.

\section{TABLE IX}

REPRODUCIBILITY OF 38 AUGMENTED HISTAMINE TESTS ON 17 PATIENTS

\begin{tabular}{lcr} 
& $\begin{array}{l}\text { Mean } \\
\text { Coefficient of } \\
\text { Variation }\end{array}$ & S.D. \\
\hline B.A.O. & $13 \%$ & 13 \\
M.A.O. & $7 \%$ & 5
\end{tabular}

While the value for M.A.O. $(7 \%)$ is well within accepted limits, of particular interest is the not too high a coefficient of variation $(13 \%)$ obtained for the basal acid output. The basal acid output has been held to be notoriously variable, subject to psychic stimuli and other factors. But it seems possible to minimize the influence of these during the course of the test and obtain a basal state which appears to be reproducible with not too big a variation.

A high B.A.O. has been observed in this study in hookworm subjects compared with the normal controls. This assumes significance, especially as the control group was comparable to the hookworm group with regard to age, sex, weight, haemoglobin values, nutritional status, etc. The method of testing acid secretion was similar in the two groups and under similar conditions; careful consideration was also given to possible extraneous factors influencing the results. In a separate study smoking habits as well as the consumption of coffee, tea, as well as alcohol (information obtained by a detailed questionnaire), seemed to have no effect on gastric acid secretion. It appears reasonable to consider the high basal acid output to be in some way related to hookworm infestation.

The M.A.O. values (Tables V and VI) obtained in the three different groups indicate that the parietal cell mass is very similar in 'normals' and hookworm subjects, and definitely less than in the ulcer group.

The B.A.O./M.A.O. values in the three groups show interesting features. It seemed reasonable to fractionate the duodenal ulcer sample for different ranges of M.A.O. Nevertheless, the B.A.O./M.A.O. ratio bears a striking similarity, almost a constant, for the range $10 \mathrm{mEq}$. to $40 \mathrm{mEq}$. of maximal acid secretion. An interesting gradient is thus encountered, ranging from $15 \%$ for normals, $24 \%$ for ancylostomiasis, and to about $27 \%$ in most patients with peptic ulcer. It remains to be seen whether the B.A.O./ M.A.O. ratio yields a valuable dimension towards further understanding of the role of acid secretion as a causative factor in the genesis of duodenal ulceration.
Attention has been drawn recently to a syndrome (Fraser, Pitman, Lawrie, Smith, Forrest, and Rhodes, 1964) where gastric hypersecretion is associated with duodenal mucosal changes as witnessed in the present study. Patients studied by these authors presented with symptoms indistinguishable from chronic peptic ulcer and showed very high histamine-induced acid levels. The suggestion was entertained that a number of subjects with the above syndrome with superadded hookworm infestation might have been included in our material. This appears improbable as a histamine highinduced secretion was not evident in our subjects with ancylostomiasis. In fact, the post-histamine acid secretion in the latter group was not different from that in the 'normal controls'.

The enigma of the increased basal acidity in the hookworm group justifies, albeit as a hypothesis only, consideration of the recent discovery of the duodenum as a rich source of gastrin. Parasitic duodenitis may, perhaps, set up a higher basal stimulation; can it be termed a 'gastrin hypertonus'? It needs a reminder here that the high basal acid secretion of the Zollinger-Ellison syndrome has been proved to be mediated by a gastrin or gastrin-like substance extracted from the tumour (Gregory, Tracy, French, and Sircus, 1960). In the absence of histopathological studies of the precise nature of this parasitic inflammation and the mechanism of the suggested gastrin release remaining far from clear, any further attempt at an explanation runs the risk of turning a mere hypothesis for further scientific study into a state of speculative charlatanism.

The question as to whether an already inflamed and injured duodenum will not break down into peptic ulceration, under the influence of a higher basal acid influx, is interesting. Furthermore, not infrequently the clinical picture of such duodenitis resembles closely that of chronic peptic ulcer. The symptoms have often satisfactorily resolved with adequate antihelmintic treatment. In this context one must consider certain distinct and special features of chronic duodenal ulcer as met with in South India. These include a high incidence in childhood (Ganguli, Narielvala, Ahmed, Bhat, and Benjamin, 1963) the frequent distal bulbar or postbulbar site of the ulcer (Paterson and Hancock, 1958), a greater preponderance of duodenal cicatrizing stenosis, and a relatively low incidence of perforation. To this must be added the somewhat different pattern of acid secretion than reported in the West, namely, that the mean basal acid output has been high in our subjects in spite of only a slight elevation of the mean maximal acid output (Raju, Ganguly, Bhat, and Narielvala, 1965).

The coexistence of ancylostomiasis and chronic 


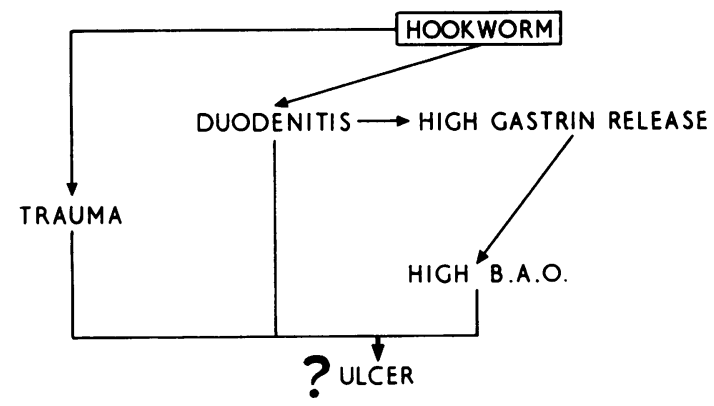

FIG. 3. Possible relationship between ancylostomal duodenitis and peptic ulcer.

duodenal ulcer has yet to be well documented. An analysis of our hospital statistics showed the incidence of chronic duodenal ulcer to be not more than $5 \%$ among the in-patient population. But the incidence of ulcer was higher at $15 \%$ in a group with hookworm ova detected in their stools during 'routine' examination of faeces. The enigma of precise causative factors for chronic duodenal ulcer remains complex and probably multifactorial. Nevertheless a possible hypothetical scheme of events is postulated for further investigation (Fig. 3). Figure 3 attempts to link the finding of increased basal acid secretion in ancylostomiasis with the suggested excessive gastrin release secondary to the 'duodenitis' and this in turn may constitute a precursor state for subsequent duodenal ulceration.

We wish to thank Mr. A. Prakasham for technical help, and Messrs. Richard and Jesudian who helped in the statistical computation of the data.

\section{REFERENCES}

Baker, S. J., Mathan, V. I., and Joseph, I. (1963). The epidemiology of tropical sprue. In Proc. 2nd Wld Congr. Gastroent., vol. 2, pp. 4-7. Karger, Basel and New York.

Bonne, C. (1942). Invasion of the wall of the human intestine by ancylostomes. Amer. J. trop. Med., 22, 507-509.

Card, W. I., and Marks, I. N. (1960). The relationship between the acid output of the stomach following 'maximal' histamine stimulation and the parietal cell mass. Clin. Sci., 19, 147-163.

Centerwall, W., and Narielvala, F. M. (1964). Unpublished data.

Fraser, G. M., Pitman, R. G., Lawrie, J. H., Smith, G. M. R., ForrestA. P. M., and Rhodes, J. (1964). The significance of the radiological finding of coarse mucosal folds in the duodenum. Lancet, 2, 979-982.

Ganguli, P. C., Narielvala, F. M., Ahmed, I., Bhat, H. S., and Benjamin, V. (1963). Childhood peptic ulcer in South India: incidence, clinical picture and results of treatment. In Proc. Wld Congr. Gastroent., vol. 2, pp. 399-421. Karger, Basel and New York.

Gregory, R. A., Tracy, H. J., French, J. M., and Sircus, W. (1960). Extraction of a gastrin-like substance from a pancreatic tumour in a case of Zollinger-Ellison syndrome. Lancet, 1, 1045-1048.

Hodes, P. J., and Keefer, G. P. (1945). Hookworm disease. Amer. J. Roentgenol., 54, 728-742.

Kay, A. W. (1953). Effects of large dose of histamine on gastric secretion of $\mathrm{HCl}$ : an augmented histamine test. Brit. med. J., 2, 77-80.

Marks, I. N. (1961). The augmented histamine test. Gastroenterology, 41, 599-603.

Lai Kai Sum (1963). A method for bioassay of gastrin and its application to the study of human tissues. In Surgical Physiology of the Gastrointestinal Tract, pp. 85-89, edited by A. Smith, Royal College of Surgeons, Edinburgh.

Paterson, D. E., and Hancock, D. M. (1958). Duodenal stenosis due to post-bulbar ulcer. Brit. J. Radiol., 31, 660-665.

Raju, S., Ganguly, P. C., Bhat, H. S., and Narielvala, F. M. (1965). The place of augmented histamine test as a study of gastric acid secretion. J. Ass. Physns of India, 13, 399-400.

Rao, B. R. H., Klontz, C. E., Benjamin, V., Rao, P. S. S., Almas Begum, and Dumm, M. E. (1960). Nutritional status survey of the rural population in Sholavaram. J. Indian med. Ass., 35, 259-266.

Stoll, N. R. (1923). Investigations of the control of hookworm disease. $X V$. An effective method of counting hookworm eggs in feces. Amer. J. Hyg., 3, 59-70. 